\title{
O TRANSPORTE INTERURBANO NO BRASIL E SUA INFRAESTRUTURA DE APOIO
}

Ana Clara Ribeiro de Sousa, Korina Aparecida Teixeira Ferreira da Costa.

Universidade do Oeste Paulista - UNOESTE, Curso de Arquitetura e Urbanismo, Presidente Prudente, SP. Email:anasousa.arq3@gmail.com.

\section{RESUMO}

O estudo teve como objetivo contextualizar brevemente o modal rodoviário, e apontar seu desenvolvimento no Brasil e funcionalidade no âmbito urbano. Apresentou análises concisas de três obras arquitetônicas para que, a partir delas seja possível compreender a aplicação dos terminais rodoviários em diversas localidades, cada qual com suas necessidades específicas, com intuito de atender mais eficientemente seus usuários. Assim ressalta-se o valor desse equipamento urbano e a importância de ser projetado e implantado com planejamento e organização, que confiram à cidade um elemento arquitetônico dotado de funcionalidade e influências positivas para o desenvolvimento de sua sociedade. A metodologia constou pesquisa qualitativa, com a utilização de livros e meios eletrônicos para consulta.

Palavras-chave: transporte, rodoviarismo, funcionalidade, terminal rodoviário, arquitetura.

\section{THE INTERCITY TRANSPORTATION IN BRAZIL AND SUPPORT INFRASTRUCTURE}

\section{ABSTRACT:}

The purpose of the study was to contextualize briefly the road modal, pointing to its development in Brazil and functionality in the urban context. There were presented concise analyzes of three architectural installations so that, from them, it is possible to understand the application of the road terminals in several locations, each one with its specific needs, in order to serve its users more efficiently. It highlights the value of this urban equipment and the importance of being designed and implemented with planning and organization that give the city an architectural element endowed with functionality and positive influences for the development of this society. The methodology consisted of qualitative research, with the use of books and electronic means for consultation.

Keywords: transport, road transport, functionality, bus terminal, architecture. 


\section{INTRODUÇÃO}

Ao longo dos anos, foram inventados vários meios de transporte que progrediram em prol do atendimento com maior eficiência, conforto e rapidez. O declínio do modal ferroviário por volta dos anos 1960 resultou do potencial do transporte rodoviário em evidência, que com a influência de políticas que aliavam a indústria e o rodoviarismo se consolidou no Brasil. Com a diversidade e a flexibilidade das vias que interligam grande parte do território nacional, tornou-se um dos mais utilizados para o transporte não somente de pessoas, como também de cargas.

O desenvolvimento das cidades e seu povoamento estão diretamente ligados à mobilidade. Assim, os transportes e seu pontos de apoio devem ser considerados relevantes para a urbanidade. Desse modo entende-se a relevância desses equipamentos urbanos e aponta-se a necessidade de reconhecer e planejar seus espaços em conformidade com normativas e necessidades individuais dos locais nos quais são implantados.

Os terminais rodoviários são os elementos mediadores entre o passageiro e o deslocamento. Nele podem ser oferecidos serviços que auxiliem a viagem e o período de espera. A arquitetura desses espaços pode ser bem singular como evidenciou objetivamente os estudos de três interessantes e expressivos terminais.

\section{METODOLOGIA}

O desenvolvimento dos estudos foi fundamentado em pesquisa qualitativa. Dessa forma, os embasamentos teóricos que objetivam aumentar o conhecimento referente ao tema, serão formulados a partir da pesquisa bibliográfica, que será realizada a partir de registros tangentes à temática, como livros, revistas físicas e eletrônicas e artigos científicos.

$O$ estudo se distribuiu em um contexto do rodoviarismo, desde o início de seu desenvolvimento até o compreendimento da relevância de sua implantação. Dados esses conhecimentos, foi possível analisar, em âmbito arquitetônico, obras consideradas pertinentes para estudo.

\section{RESULTADOS}

Os transportes são entendidos como meios de superar distâncias somado aos valores de comodidade e agilidade. Estão diretamente ligados ao potencial de desenvolvimento econômico e social das cidades e à vivência de seus moradores (GOUVEIA, 2013).

Os modais de transporte se enquadram nos âmbitos terrestre, aquático e aéreo, dos quais se destacam o rodoviário e ferroviário. O transporte ferroviário foi predominantemente utilizado para cargas, porém sua limitada malha viária abriu espaço para que novos meios de locomoção se desenvolvessem para melhor satisfazer a população (CNT, 2014 apud COLAVITE, KONISHI, 2015).

Com uma política de desenvolvimento que prezava o rodoviarismo, por volta dos anos de 1930, o transporte rodoviário foi largamente potencializado com a construção de estradas, o que fomentou o empreendedorismo e o povoamento. Assim, o transporte de cargas e pessoas foi conciliado (BRASILEIRO; HENRY, 1999).

O ônibus interurbano foi decorrente da pavimentação das estradas e possibilitou maiores conexões nacionais. Em São Paulo, o transporte coletivo data dos anos de 1865 e ao longo dos anos foram fundados companhias e ministérios para incentivar esse meio (SÃO PAULO, SPTRANS, 2006). 
Como infraestrutura de apoio a esse transporte, tem-se os terminais rodoviários, que fazem a articulação intermunicipal e interestadual (LAROUSSE, 1998 apud CARVALHO; BECHELLI, 2012). Soares (2006, p. 17) conceitua um Terminal Rodoviários de Passageiros (TRP):

O TRP é uma estação de transporte onde aportam viajantes em trânsito entre duas cidades, saindo ou chegando das cidades, constituindo-se no ponto extremo das viagens realizadas, principalmente, pelo transporte interurbano de passageiros de média e longa distância, representando a interface, o elo dos usuários, viajantes do sistema com a cidade.

\section{DISCUSSÃO}

Para o aprofundar o conhecimento e entender a sistemática dos terminais, foram analisadas três obras arquitetônicas: a Antiga Rodoviária de Londrina, a Central Rodoviária de Rio Maior e o Terminal de Ônibus de Kayseri.

A Antiga Rodoviária de Londrina compreende um edifício tombado como patrimônio histórico e artístico, com escala dimensional reduzida quando comparada aos terminais de grandes metrópoles. Está situada centralmente à cidade de Londrina, no estado do Paraná, projetada por Villanova Artigas em 1948 e atualmente abriga o Museu de Arte (LIASCH, 2011).

O edifício confere uma arquitetura moderna, inovadora para a época por conta do emprego do concreto armado em uma cobertura abobadada nas plataformas. O volume principal dispõe seu programa em 4 pavimentos, acessados por rampas. Este consiste nos setores administrativo (guichês) e de serviços diversos (restaurante, espera, apoio e lojas) (LEMOS, 2007).

Com base nos estudos do projeto do terminal no terreno pode-se perceber que a implantação possibilitou a criação de acessos distintos, com funções bem demarcadas. Pela rua defronte ao terminal tem-se o acesso de pedestres caracterizada por uma marquise que antecede a entrada do edifício. Pela rua lateral o acesso é destinado aos ônibus que estacionam nas plataformas de embarque e desembarque. Nota-se que a separação dos acessos foi muito relevante para garantir uma circulação segura e ordenada. Os estudos de insolação também foram relevantes para a vedação do edifício com painéis de vidro na fachada sul, que recebe baixa insolação direta. Entretanto, a fachada sul recebeu brises móveis para auxiliar no aproveitamento da iluminação natural de maneira confortável no espaço interno. A utilização do vidro favorece as relações do exterior com o interior, pois ao circular pelo edifício, o usuário tem a vista de seu entorno.

A Central Rodoviária de Rio Maior foi projetada por Domitianus Arquitectura, em 2005 e está situado em Portugal. O foco do projeto se ateve ao conforto de seus usuários de maneira que este, se tornasse um ícone da identidade visual local (HELM, 2011). O estudo de entorno evidenciou que há predominância de áreas destinadas ao lazer e não se apresentam edificações habitacionais, fator contribuinte para preservar o conforto acústico e de tráfego para esses moradores.

A partir da análise do projeto, verificou-se que o edifício foi implantado horizontalmente ao terreno, condição que confere leveza ao conjunto e determinada correspondência atrelada ao gabarito de altura da localidade. Suas três paredes vedadas com vidro, garantem uma continuidade visual que atrela o espaço interno com a paisagem circundante. Além disso, possui pé direito duplo, que aliado com a distribuição dos espaços e do mobiliário, contribui para a amplitude interna. As entradas do saguão acompanham a materialidade dos painéis de vidro e são acessadas por meio de uma escadaria e rampa 
direcionadas para as plataformas de embarque e desembarque, que por sua vez, são cobertas por uma laje plana apoiada sobre sólidos pilares arredondados. A laje, de concreto armado, segue como elemento único para a cobertura do volume interno, para a parede da fachada sul e piso, que apoiada sobre uma fundação abaixo do nível principal, denota a sensação de flutuar na paisagem. Em paralelo à Ching, constatou-se uma subtração do volume retangular, devido as arestas arredondadas, que concede dinamismo ao conjunto que remete a velocidade dada sua forma.

$\mathrm{Na}$ análise da planta baixa observou-se um programa sucinto e com circulação eficiente que compreende saguão, lanchonete, guichê, sanitários e administração, esta, situada isoladamente no primeiro pavimento.

O Terminal de Ônibus de Kayseri foi projetado em 2006 e com construção finalizada em 2009, por Bahadir Kul Architects, em Kayseri, Turquia. Resultou de uma política de desenvolvimento urbano que preza por elementos que pudessem compor uma paisagem agradável à cidade. Desse modo, foram empregados vidro e blocos de concreto em um edifício com formato singular (KAYSERI, 2017).

A partir de análises de seu entorno, pode-se observar que o arrojado edifício está afastado do principal centro, porém com outros modais em sua vizinhança, aspecto que facilita os deslocamentos intra e interurbano, sem causar fluxo intenso nos pontos de circulação centrais. $O$ terminal possui um formato que remete à horizontalidade, que se conforma com as alturas dos edifícios próximos.

No projeto nota-se as distribuições de usos bem definidas e separadas: estacionamentos de carros para usuários e área de ônibus destinada ao embarque e desembarque de passageiros. Nessa área, verifica-se alguns aspectos que diminuem a eficiência e agilidade no serviço, como a disposição das plataformas em alinhamento vertical, que dificultam as manobras e impossibilitam um calçamento avançado para acessar os ônibus. Por outro lado, a disposição de entrada e saída distintas é muito eficaz ao equipamento urbano. O edifício possui 3 entradas, que bem locadas, otimizam 0 funcionamento do terminal, segundo suas funções. Todas elas são direcionadas ao saguão que se estende ao longo da obra. Nele se distribui o programa, que em uma unidade concentra guichês, sala de oração, sala de controle de temperatura, administração e sanitários. Ao final dessa grande circulação há outros guichês de atendimento. A obra, em forma de " $Z$ " com adições, possui linhas diagonais na disposição de suas partes de cobertura e pilares de sustentação, que denota ao conjunto um aspecto tecnológico que condiz ao terminal e até mesmo causar uma sensação de desequilíbrio.

\section{CONCLUSÃO}

O estudo do modal rodoviário, conduzido desde sua evolução e utilização no Brasil, bem como seu terminal e diversas obras que envolvem a temática, são relevantes para o meio social que engloba a evolução organizacional das cidades, associada ao urbanismo.

Esses estudos introduzem ao conhecimento dos terminais rodoviários que com maior aprofundamento possibilitam, juntamente com a prática de projeto, o discernimento e a capacidade de planejar um terminal rodoviário alie a funcionalidade às particularidades conferidas ao local no qual será inserido.

A sociedade está condicionada a utilizar elementos dispostos no meio urbano, na maioria das vezes sem a percepção da real necessidade, funcionalidade e a forma na qual tal elemento foi planejado. Assim, o estudo apontou aos leitores o progresso do modal e 
maneiras de como o terminal rodoviário pode ser disposto e construído, por ressaltar seus valores arquitetônicos. Assim, um edifício de função comum, pode ser amplamente compreendido dada sua relevância na escala regional que abrange.

Desse modo entende-se que a apresentação do tema foi determinante para compreender suas atribuições enquanto modal e equipamento urbano e as relações inerentes ao meio urbano e seus usuários.

\section{REFERÊNCIAS}

BRASILEIRO, A.; HENRY, E. Viação Ilimitada: Ônibus das Cidades Brasileiras. 1. ed. São Paulo: Cultura Editores Associados, 1999. cap. 1: Secretaria de Viação, fabricação e promoção do sistema ônibus brasileiro, p. 47-65.

CARVALHO, A. C. P.; BECHELLI, C. B. Busca de informação: Tipologias e diretrizes de projeto dos terminais rodoviários de passageiros. I Simpósio Nacional de Iniciação Científica: Práticas em Iniciação Científica, Londrina, v. 1, p. 125-126, 2012. Disponível em: $<$ http://www.unifil.br/portal/images/pdf/ documentos/livros/praticas-em-iniciacaocientifica.pdf $>$. Acesso em: 6 mar. 2018.

COLAVITE, A. S.; KONISHI, F. A matriz do transporte no Brasil: uma análise comparativa para a competitividade. XII Simpósio de Excelência em Gestão e Tecnologia, Resende, p. 1-7, 2015. Disponível em: <https://www.aedb.br/seget/arquivos/artigos15/802267.pdf>. Acesso em: 13 mar. 2018.

GOUVEIA, A. A. M. Regulação do transporte rodoviário coletivo de passageiros. 2013. 99 f. Dissertação (Mestrado em Planejamento e Projeto Urbano) - Faculdade de Engenharia, Universidade do Porto, Porto, Portugal, 2013.

HELM, J. Terminal Rodoviário em Rio Maior / Domitianus Arquitectura, 2011. Disponível em: <https://www.archdaily.com.br/br/01-7415/terminal-rodoviario-em-rio-maiordomitianusarquitectura>. Acesso em: 23 fev. 2018.

KAYSERI. Missão e visão, 2017. Disponível em: <https://www.kayseri.bel.tr/misyon-vevizyon>. Acesso em: 28 mar. 2018.

LEMOS, A. M. B. Portais urbanos rodoviários, 2007. Pós Graduação em Arquitetura Programa de Pesquisa e Pós-Graduação em Arquitetura da Universidade Federal do Rio Grande do Sul. 160 f. Disponível em: <http://hdl.handle.net/10183/11043>. Acesso em: 24 mar. 2018.

LIASCH, J. As antigas estações rodoviárias de Londrina, 2011a. Disponível em: $<$ http://londrinahistorica.blogspot.com.br/2011/05/as-antigas-estacoes-rodoviariasde.html>. Acesso em: 1 mar. 2018.

SÃO PAULO. Secretaria de Transporte. SPTRANS. Cronologia do transporte coletivo em São Paulo, $2006 . \quad$ Disponível em: <http://www.sptrans.com.br/museu/cronologia_transporte.pdf>. Acesso em: 14 mar. 2018. 
SOARES, U. P. Procedimento para a localização de terminais rodoviários interurbanos, interestaduais e internacionais de passageiros. 2006. 343 f. Dissertação (Mestrado em Engenharia de Transportes) - Universidade Federal do Rio de Janeiro COPPE, Rio de Janeiro. 2006. 